\title{
Radiographic outcome and complications after single-level lumbar extended pedicle subtraction osteotomy for fixed sagittal malalignment: a retrospective analysis of $\mathbf{5 5}$ adult spinal deformity patients with a minimum 2-year follow-up
}

\author{
${ }^{*}$ Thomas J. Buell, MD, James H. Nguyen, MD, Marcus D. Mazur, MD, Jeffrey P. Mullin, MD, \\ Juanita Garces, MD, Davis G. Taylor, MD, Chun-Po Yen, MD, Mark E. Shaffrey, MD, \\ Christopher I. Shaffrey, MD, and Justin S. Smith, MD, PhD
}

Department of Neurological Surgery, University of Virginia Health System, Charlottesville, Virginia

\begin{abstract}
OBJECTIVE Fixed sagittal spinal malalignment is a common problem in adult spinal deformity (ASD). Various threecolumn osteotomy techniques, including the extended pedicle subtraction osteotomy (ePSO), may correct global and regional malalignment in this patient population. In contrast to the number of reports on traditional PSO (Schwab grade 3 osteotomy), there is limited literature on the outcomes of ePSO (Schwab grade 4 osteotomy) in ASD surgery. The objective of this retrospective study was to provide focused investigation of radiographic outcomes and complications of single-level lumbar ePSO for ASD patients with fixed sagittal malalignment.
\end{abstract}

METHODS Consecutive ASD patients in whom sagittal malalignment had been treated with single-level lumbar ePSO at the authors' institution between 2010 and 2015 were analyzed, and those with a minimum 2-year follow-up were included in the study. Radiographic analyses included assessments of segmental lordosis through the ePSO site (sagittal Cobb angle measured from the superior endplate of the vertebra above and inferior endplate of the vertebra below the ePSO), lumbar lordosis (LL), pelvic tilt (PT), pelvic incidence and LL mismatch, thoracic kyphosis (TK), and sagittal vertical axis (SVA) on standing long-cassette radiographs. Complications were analyzed for the entire group.

RESULTS Among 71 potentially eligible patients, $55(77 \%)$ had a minimum 2-year follow-up and were included in the study. Overall, the average postoperative increases in ePSO segmental lordosis and overall LL were $41^{\circ} \pm 14^{\circ}$ (range $7^{\circ}-69^{\circ}, p<0.001$ ) and $38^{\circ} \pm 11^{\circ}$ (range $9^{\circ}-58^{\circ}, p<0.001$ ), respectively. The average SVA improvement was $13 \pm 7 \mathrm{~cm}$ (range of correction: -33.6 to $3.4 \mathrm{~cm}, p<0.001$ ). These measurements were maintained when comparing early postoperative to last follow-up values, respectively (mean follow-up 52 months, range $26-97$ months): ePSO segmental lordosis, $34^{\circ}$ vs $33^{\circ}, p=0.270 ; \mathrm{LL}, 47.3^{\circ}$ vs $46.7^{\circ}, p=0.339$; and SVA, 4 vs $5 \mathrm{~cm}, p=0.330$. Rod fracture (RF) at the ePSO site occurred in $18.2 \%(10 / 55)$ of patients, and pseudarthrosis (PA) at the ePSO site was confirmed by CT imaging or during rod revision surgery in $14.5 \%$ (8/55) of patients. Accessory supplemental rods across the ePSO site, a more recently employed technique, significantly reduced the occurrence of RF or PA on univariate $(p=0.004)$ and multivariable (OR $0.062,95 \% \mathrm{Cl} 0.007-0.553, p=0.013)$ analyses; this effect approached statistical significance on Kaplan-Meier analysis ( $p=0.053$, log-rank test). Interbody cage placement at the ePSO site resulted in greater ePSO segmental lordosis correction $\left(45^{\circ}\right.$ vs $\left.35^{\circ}, p=0.007\right)$ without significant change in RF or PA $(p=0.304)$. Transient and persistent motor deficits occurred in $14.5 \%(8 / 55)$ and $1.8 \%$ (1/55) of patients, respectively.

CONCLUSIONS Extended PSO is an effective technique to correct fixed sagittal malalignment for ASD. In comparison to traditional PSO techniques, ePSO may allow greater focal correction with comparable complication rates, especially with interbody cage placement at the ePSO site and the use of accessory supplemental rods.

https://thejns.org/doi/abs/10.3171/2018.7.SPINE171367

KEYWORDS spine surgery; adult spinal deformity; scoliosis; fusion; pedicle subtraction osteotomy; rod fracture; pseudarthrosis; lumbar

ABBREVIATIONS ASD = adult spinal deformity; $\mathrm{ePSO}=$ extended PSO; FSM = fixed sagittal spinal malalignment; $\mathrm{LL}=$ lumbar lordosis; $\mathrm{PA}=\mathrm{pseudarthrosis} ; \mathrm{PI}=$ pelvic incidence; PSO = pedicle subtraction osteotomy; PT = pelvic tilt; RF = rod fracture; $S V A=$ sagittal vertical axis; $T K=$ thoracic kyphosis.

SUBMITTED December 10, 2017. ACCEPTED July 10, 2018.

INCLUDE WHEN CITING Published online November 9, 2018; DOI: 10.3171/2018.7.SPINE171367.

${ }^{*}$ C.I.S. and J.S.S. share senior authorship. 
$\mathrm{F}$ IXED sagittal spinal malalignment (FSM) is a condition in which the weight-bearing line is displaced anterior to the sacrum. ${ }^{1,3,6}$ Numerous adult spinal deformity (ASD) studies have demonstrated a significant correlation between sagittal malalignment and patient-reported clinical outcome measures such as worse back pain, increased disability, and an overall reduction in health-related quality of life..$^{23,24,37}$ Fixed sagittal spinal malalignment can occur after previous spinal fusion operations and has been cited as a potential long-term complication following Harrington distraction instrumentation. $2,4,13,18,21,29,31$

Many studies have demonstrated significant improvements in patient-reported clinical outcomes after operative management of appropriately selected ASD patients if proper global, regional, and spinopelvic alignment are restored., ${ }^{1,22,29,36,40,41,49}$ There are many osteotomy techniques for alignment correction, and the most commonly performed technique is the posterior column osteotomy (e.g., Smith-Petersen osteotomy and Ponte osteotomy); however, three-column osteotomy techniques may be required for greater correction of more severe ASD cases with FSM. 2,6,7,12,15,22 Most scoliosis literature focuses on the Schwab grade 3 pedicle subtraction osteotomy (PSO), ${ }^{35}$ or "traditional" PSO, 1,3,6,7,29,49 which involves extensive resection of the posterior elements, pedicles, and vertebral body through a posterior approach. ${ }^{6,7,29}$ For this technique, the superior endplate of the index vertebra and the upper intervertebral disc are left intact.6,7,29 However, ASD patients with more severe FSM may require greater angular correction, and extending the posterior wedge resection of the index vertebra to include removal of the superior endplate and adjacent superior disc ("transdiscal" or "extended" PSO [ePSO], Schwab grade 4 osteotomy) may be beneficial. , $^{935}$

In contrast to the number of reports on traditional PSO (Schwab grade 3 osteotomy), 1,3,6,7,29,49 there is limited literature on ePSO (Schwab grade 4 osteotomy) for ASD surgery. The objective of the present study was to provide focused investigation of radiographic outcomes and complications of single-level lumbar ePSO for ASD patients with FSM.

\section{Methods}

We performed a retrospective analysis of a prospectively collected database of ASD patients who had undergone single-level lumbar ePSO for fixed global or regional sagittal malalignment. Sagittal spinal malalignment (global or regional) was defined by at least one of the following radiographic measures: sagittal vertical axis (SVA) or C7 plumbline $\geq 5 \mathrm{~cm}$, pelvic tilt $(\mathrm{PT}) \geq 25^{\circ}$, pelvic incidence (PI) and lumbar lordosis (LL) mismatch $\geq 10^{\circ}$, or thoracic kyphosis (TK) from T5 to T12 $\geq 60^{\circ}$. Adult patients $\geq 18$ years old who had complete radiographic data with preoperative, early postoperative (most commonly 6 weeks postoperative), and final standing long-cassette films at a minimum 2-year follow-up were included. Patients were excluded if there was evidence of active vertebral osteomyelitis/discitis. All operations had been performed by the two senior authors (C.I.S., J.S.S.) at the University of Virginia Health System between the years 2010 and 2015.
The study was approved by the University of Virginia Institutional Review Board.

\section{Extended PSO Technique}

All patients underwent posterior instrumented fusion (could have had concomitant staged anterior fusion) combined with a posterior-based closing wedge osteotomy at a single lumbar level. In contrast to the traditional PSO (Schwab grade 3 osteotomy), the ePSO technique (Schwab grade 4 osteotomy) utilized in this study involves further resection of the superior portion of the vertebral body into the disc space for radical discectomy (Fig. 1A).

Our ePSO technique involves first performing wide posterior decompression of the index level from pedicle to pedicle. ${ }^{9}$ Then the pedicles are completely removed and made flush with the vertebral body. The psoas musculature along the lateral aspect of the vertebral body is dissected free. With a spoon-shaped retractor placed along the anterior aspect of the vertebral body to protect the great vessels, we resect a triangular, tricortical portion of the superior aspect of the vertebral body, including the superior endplate. We then perform radical discectomy with total removal of the cartilaginous inferior endplate of the vertebral body at the level above the osteotomy. A short, temporary rod is attached to pedicle screws on either side of the osteotomy to provide stability and prevent premature closure of the osteotomy. The extensive wedgeshaped resection is then completed, leaving only the anterior longitudinal ligament and a thin rim of cortical bone. These steps are performed from both sides.

Next, the residual portion of the posterior vertebral body wall ventral to the dural sac is impacted into the decancellated wedge defect, and the posterior longitudinal ligament is removed. An interbody cage spacer can be placed at the osteotomy site to act as a fulcrum for additional lordosis or to increase the contact surface area for arthrodesis (Fig. 1B). Indications for cage placement at the PSO defect include incomplete bony apposition and/or excessive dural buckling while closing the osteotomy defect. Unless contraindicated, we typically implant off-label recombinant human bone morphogenic protein-2 (rhBMP-2) at the osteotomy site to promote interbody bony fusion at the wedge defect. Finally, the temporary rod is loosened, and cantilever and compressive forces are applied to close the posterior wedge osteotomy. Hyperextension of the patient's hips and legs facilitates osteotomy closure. Permanent rods are placed to secure the new lordotic position of the spine. Beginning in August 2012 (C.I.S.) and April 2013 (J.S.S.), accessory supplemental rods were then attached to the primary rods and spanned the ePSO; the majority were 4-rod constructs (62\% [18/29]).

\section{Radiographic Measurements}

Subjects had standing posteroanterior and lateral longcassette $(14 \times 36$ inches $)$ radiographs at the preoperative baseline, early postoperative follow-up (usually 6 weeks following surgery), and final follow-up. The following parameters were measured: ePSO segmental lordosis (sagittal Cobb angle measured from the superior endplate of the vertebra above and inferior endplate of the vertebra below 
A Traditional PSO (Schwab grade 3 osteotomy)
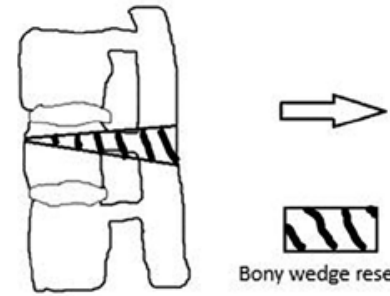

ताV

Bony wedge resection

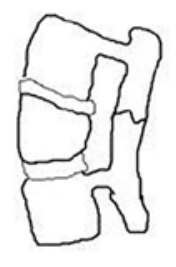

Extended PSO (Schwab grade 4 osteotomy)

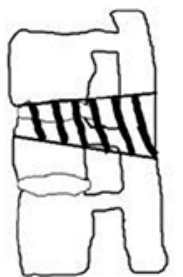

\section{ताV}

Bony wedge resection

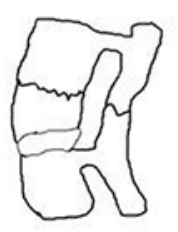

and radical discectomy
B Extended PSO (Schwab grade 4 osteotomy) with Interbody Cage Spacer

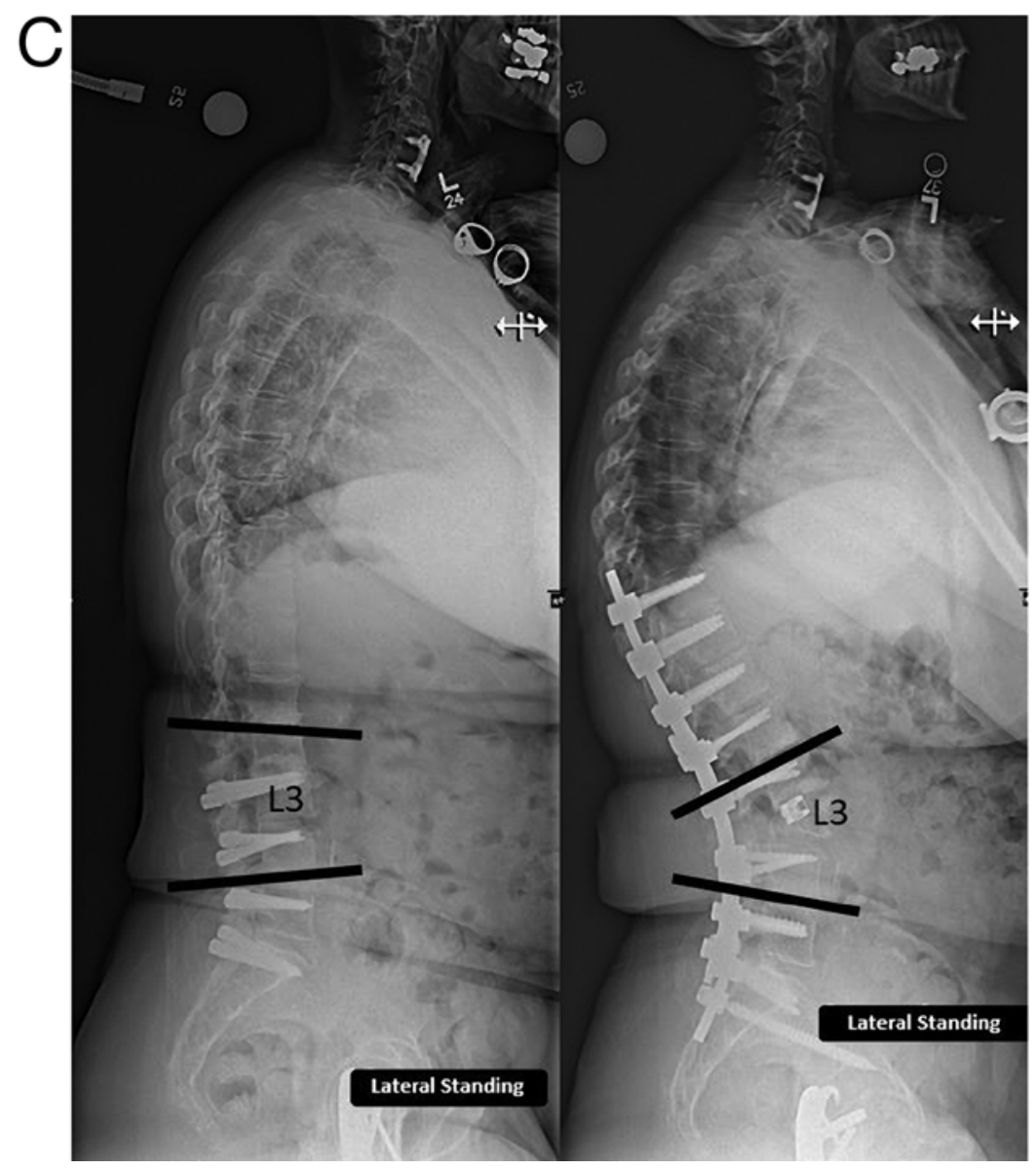

FIG. 1. A: The classic or traditional PSO technique, which is classified as Schwab grade 3 osteotomy. ${ }^{35}$ The posterior closing bony wedge resection respects the superior endplate of the index vertebra and adjacent superior disc space. Also note the ePSO technique (Schwab grade 4 osteotomy), which was utilized by the two senior authors (C.I.S., J.S.S.) in this study. The wedge resection is extended superiorly to include the adjacent disc space for radical discectomy. B: An interbody cage spacer can be placed at the osteotomy site to act as a fulcrum for additional lordosis or to increase the contact surface area for arthrodesis. C: Preoperative (left) and postoperative (right) long-cassette standing scoliosis radiographs for a 65-year-old woman who presented with thoracolumbar kyphoscoliosis above a previous L3-S1 dynamic stabilization system. She underwent surgical correction with an ePSO at L3, interbody cage placement at the ePSO site, and re-instrumentation for fusion from T10 to iliac. In this case, the L3 ePSO segmental lordosis is the sagittal Cobb angle measured between the L2 superior endplate and L4 inferior endplate. The early postoperative change in ePSO segmental correction measured $41^{\circ}$. 
the ePSO; Fig. 1C), overall LL, PT, PI-LL mismatch, TK (T5-12), and SVA. Angles were considered negative (-) if lordotic and positive $(+)$ if kyphotic. Collection and review of radiographic data and medical charts were performed by neurosurgery complex spine fellows and senior residents independent of the two senior operating neurosurgeons (C.I.S., J.S.S.).

\section{Statistical Analyses}

Data are presented as the mean \pm standard deviation for continuous variables and as the frequency with percentage for categorical variables. Statistical analyses were performed using SPSS, version 24.0 (IBM Corp.). Univariate analyses included the paired samples t-test, independent samples t-test, and Fisher exact test. For multivariable analysis, variables associated with a $\mathrm{p}$ value $<0.15$ on univariate comparisons were entered in a binary logistic regression model. Goodness-of-fit was assessed using the Hosmer-Lemeshow test. ${ }^{44}$ Kaplan-Meier survivorship analysis was performed to analyze the occurrence of rod fracture (RF) or pseudarthrosis (PA) in a time-dependent fashion. All tests were two-tailed, and $\mathrm{p}$ values $<0.05$ were considered statistically significant.

\section{Results}

\section{Patient Demographics and Surgical Data}

Among 71 potentially eligible patients, 55 (77\%) had a minimum 2-year follow-up and were included in this study (mean follow-up 52.3 months, range 26.2-97.2 months); $65.5 \%(36 / 55)$ were women, and the mean age was 64.0 \pm 10.9 years. Other demographic data are presented in Table 1 . Mean body mass index was $30.2 \pm 7.6 \mathrm{~kg} / \mathrm{m}^{2}$, mean American Society of Anesthesiologists (ASA) score was $2.6 \pm 0.6,34.5 \%(19 / 55)$ of patients had a history of osteopenia or osteoporosis recorded in the medical chart (most received treatment), 21.8\% (12/55) had a history of smoking (all patients quit smoking prior to surgery except a single patient who relapsed during the study and had delayed bony fusion), and $96.4 \%$ (53/55) had prior surgery for lumbar fusion.

Table 1 also reports data for the 55 index operations in this study. The ePSO level was L2, L3, and L4 for $38.2 \%$ $(21 / 55), 58.2 \%(32 / 55)$, and $3.6 \%(2 / 55)$ of patients, respectively; $56.4 \%$ (31/55) of patients had interbody cage placement at the ePSO site. The uppermost instrumented vertebra (UIV) was located at the upper (T2-4) versus the lower (T9-11) thoracic spine in 29.1\% (16/55) and 70.9\% (39/55) of cases, respectively. The total number of instrumented levels averaged $11.9 \pm 3.1$, and $89.1 \%$ (49/55) of patients had pelvic fixation with iliac screws. The number of rods spanning the ePSO was 2, 3, and 4 in $47.3 \%$ (26/55), $20.0 \%$ (11/55), and 32.7\% (18/55) of cases, respectively (for 3- and 4-rod constructs, accessory supplemental rods were connected to the primary rods). Rod diameter was 5.5,6.0, and $6.5 \mathrm{~mm}$ in $76.5 \%(39 / 51), 21.6 \%$ (11/51), and $2.0 \%(1 / 51)$ of cases, respectively. Mean estimated blood loss was $3.1 \pm 1.6$ $\mathrm{L}$, mean operative duration was $6.7 \pm 2.2$ hours, and mean hospital stay was $9.4 \pm 3.3$ days. Mean length of stay in the intensive care unit was $2.7 \pm 1.9$ days, and $74.5 \%$ (41/55) of patients were discharged to rehabilitation centers.
TABLE 1. Demographics and surgical data for 55 ASD patients with FSM who underwent single-level lumbar ePSO

\begin{tabular}{|c|c|}
\hline Parameter & Value \\
\hline Age at op in yrs & $64.0 \pm 10.9$ \\
\hline Female sex (\%) & $36(65.5)$ \\
\hline Body mass index in $\mathrm{kg} / \mathrm{m}^{2}$ & $30.2 \pm 7.6$ \\
\hline ASA score & $2.6 \pm 0.6$ \\
\hline Osteopenia/osteoporosis (\%) & $19(34.5)$ \\
\hline Smoking history (\%)* & $12(21.8)$ \\
\hline Prior lumbar fusion (\%) & $53(96.4)$ \\
\hline \multicolumn{2}{|l|}{ Level of ePSO (\%) } \\
\hline L2 & $21(38.2)$ \\
\hline L3 & $32(58.2)$ \\
\hline L4 & $2(3.6)$ \\
\hline Interbody cage placement at ePSO site (\%) & $31(56.4)$ \\
\hline Asymmetric ePSO for global coronal malalignment (\%) & $3(5.5)$ \\
\hline \multicolumn{2}{|l|}{ Uppermost instrumented vertebra (\%) } \\
\hline Upper thoracic spine, T2-4 & $16(29.1)$ \\
\hline Lower thoracic spine, T9-11 & $39(70.9)$ \\
\hline No. of instrumented vertebra & $11.9 \pm 3.1$ \\
\hline Iliac fixation (\%) & $49(89.1)$ \\
\hline rhBMP-2 (\%) & $53(96.4)$ \\
\hline \multicolumn{2}{|l|}{ No. of rods spanning ePSO level (\%)† } \\
\hline 2 & $26(47.3)$ \\
\hline 3 & $11(20.0)$ \\
\hline 4 & $18(32.7)$ \\
\hline \multicolumn{2}{|l|}{ Type of rods (\%) $\ddagger$} \\
\hline Cobalt chromium alloy & $52(98.1)$ \\
\hline Stainless steel & $1(1.9)$ \\
\hline \multicolumn{2}{|l|}{ Rod diameter in mm (\%)‡ } \\
\hline 5.5 & $39(76.5)$ \\
\hline 6.0 & $11(21.6)$ \\
\hline 6.5 & $1(2.0)$ \\
\hline Concomitant ant fusion (\%) & $13(23.6)$ \\
\hline Estimated blood loss in L & $3.1 \pm 1.6$ \\
\hline Op duration in hrs & $6.7 \pm 2.2$ \\
\hline Hospital stay in days & $9.4 \pm 3.3$ \\
\hline ICU stay in days & $2.7 \pm 1.9$ \\
\hline Discharge to rehabilitation & $41(74.5)$ \\
\hline
\end{tabular}

Ant $=$ anterior $; A S A=$ American Society of Anesthesiologists; $I C U=$ intensive care unit; rhBMP-2 = recombinant human bone morphogenic protein-2. Values expressed as the mean \pm standard deviation or frequency (percent) for continuous and categorical variables, respectively.

* All patients quit smoking prior to surgery except a single patient who relapsed during the study and had delayed bony fusion.

† For 3- and 4-rod constructs, accessory supplemental rods were connected to primary rods.

$\ddagger$ Rod material and size were not recorded for two and four patients, respectively.

\section{Early Postoperative Change in Radiographic Sagittal Plane Parameters}

Table 2 lists preoperative baseline, early postoperative (most commonly 6 weeks following surgery), and initial postoperative changes in the measured sagittal plane radiographic parameters. Extended PSO segmental lordosis 
improved by $40.5^{\circ} \pm 13.7^{\circ}\left(7.0^{\circ} \pm 16.8^{\circ}\right.$ vs $-33.5^{\circ} \pm 8.6^{\circ}$, $\mathrm{p}<0.001)$, overall LL improved by $38.0^{\circ} \pm 10.6^{\circ}\left(-9.3^{\circ} \pm\right.$ $15.4^{\circ}$ vs $\left.-47.3^{\circ} \pm 9.9^{\circ}, \mathrm{p}<0.001\right)$, PT decreased by $6.0^{\circ} \pm$ $8.7^{\circ}\left(33.2^{\circ} \pm 9.2^{\circ}\right.$ vs $\left.27.1^{\circ} \pm 8.3^{\circ}, \mathrm{p}<0.001\right)$, PI-LL mismatch decreased by $40.7^{\circ} \pm 13.3^{\circ}\left(52.6^{\circ} \pm 12.1^{\circ}\right.$ vs $11.9^{\circ}$ $\left.\pm 10.2^{\circ}, \mathrm{p}<0.001\right)$, TK increased by $15.1^{\circ} \pm 13.0^{\circ}\left(23.9^{\circ}\right.$ $\pm 14.5^{\circ}$ vs $\left.38.9^{\circ} \pm 11.8^{\circ}, \mathrm{p}<0.001\right)$, and SVA improved by $12.5 \pm 6.9 \mathrm{~cm}(16.8 \pm 7.8$ vs $4.4 \pm 3.4 \mathrm{~cm}, \mathrm{p}<0.001)$.

\section{Sagittal Plane Radiographic Parameters at Last Follow-Up}

Table 2 also presents segmental, regional, and global sagittal alignment changes after surgery until the final follow-up (mean follow-up 52 months, range 26-97 months). Early postoperative improvements in ePSO segmental lordosis, overall LL, and SVA were maintained at the last follow-up. The mean decrease in ePSO segmental lordosis was $0.5^{\circ} \pm 3.6^{\circ}\left(-33.5^{\circ} \pm 8.6^{\circ}\right.$ vs $\left.-32.9^{\circ} \pm 8.9^{\circ}, p=0.270\right)$, mean decrease in overall LL was $0.6^{\circ} \pm 4.6^{\circ}\left(-47.3^{\circ} \pm 9.9^{\circ}\right.$ vs $-46.7^{\circ} \pm 9.8^{\circ}, \mathrm{p}=0.339$ ), and mean increase in SVA was $0.4 \pm 3.2 \mathrm{~cm}(4.4 \pm 3.4$ vs $4.8 \pm 3.8 \mathrm{~cm}, \mathrm{p}=0.330)$ at the last follow-up.

\section{Complications After Surgical Treatment With Single-Level Lumbar ePSO}

Patients were assessed for RF primarily based on plain radiographs at follow-up unless they developed significant back pain or neurological deficit, in which case CT imaging was performed to further assess for RF and possible PA (early RF is a risk factor for PA, but late RF may be a complication of PA).$^{43}$ Rod fractures occurred either at the ePSO level $(18.2 \%$ [10/55]) or distal to the ePSO at L4-5 (5.5\% [3/55]) or L5-S1 (5.5\% [3/55]; Table 3). One patient had RFs at both the L4-5 and L5-S1 levels, for a total of 15 patients with 16 RFs. Overall, $20 \%$ of patients $(11 / 55)$ had rod revision surgery at a mean of $2.9 \pm 1.3$ years (range 1.1-5.1 years) after the index operation. Figure 2 features a case of revision surgery for RF.

Assessment for fusion was also primarily based on plain radiographs, unless excessive back pain or neurological deficits developed, which prompted CT for further evaluation. In most cases, PA was confirmed during revision surgery for RF. A total of 12 patients had PA: at the ePSO level (14.5\% [8/55]), distal to the ePSO at L4-5 (1.8\% [1/55]) or L5-S1 $(3.6 \%[2 / 55])$, or at the thoracolumbar junction (1.8\% [1/55]; Table 3). Pseudarthrosis was detected at a mean follow-up of $3.2 \pm 1.6$ years (range 1.1-6.5 years).

Transient neurological symptoms included radicular pain $(16.4 \%$ [9/55]), motor weakness $(14.5 \%$ [8/55]), and sensory deficits $(1.8 \%$ [1/55]). A neurological deficit was considered to be persistent if there was medical documentation of the deficit on $\geq 2$ clinic notes and it was present at the final follow-up. Persistent neurological deficits included radicular pain (5.5\% [3/55]) and motor weakness (1.8\% [1/55]). There were no cases of persistent sensory deficits. Of note, we routinely utilized intraoperative neurophysiological monitoring (somatosensory evoked potentials, motor evoked potentials, and electromyography [EMG]) in this study cohort. For most patients, there were no significant neuromonitoring signal changes during any aspect of the procedure. There was brief EMG activity during wedge

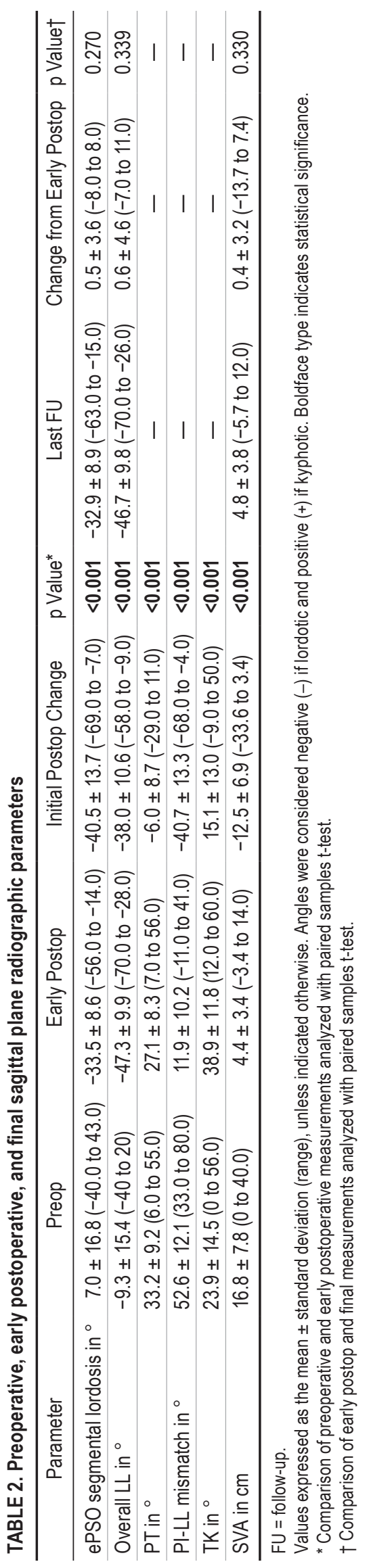


TABLE 3. Complications from single-level lumbar ePSO for FSM in 55 ASD patients

\begin{tabular}{|c|c|}
\hline Parameter & No. (\%) \\
\hline \multicolumn{2}{|l|}{$\mathrm{RF}^{*}$} \\
\hline ePSO level & $10(18.2)$ \\
\hline \multicolumn{2}{|l|}{ Distal to ePSO } \\
\hline L4-5 & $3(5.5)$ \\
\hline L5-S1 & $3(5.5)$ \\
\hline Thoracolumbar junction & $0(0.0)$ \\
\hline Revision for RF & $11(20)$ \\
\hline lliac screw fracture & $1(1.8)$ \\
\hline Pedicle screw medial breach requiring revision & $1(1.8)$ \\
\hline \multicolumn{2}{|l|}{ PA } \\
\hline ePSO level & $8(14.5)$ \\
\hline \multicolumn{2}{|l|}{ Distal to ePSO } \\
\hline L4-5 & $1(1.8)$ \\
\hline L5-S1 & $2(3.6)$ \\
\hline Thoracolumbar junction & $1(1.8)$ \\
\hline \multicolumn{2}{|l|}{ Transient neurological deficits } \\
\hline Radicular pain & $9(16.4)$ \\
\hline Motor deficit & $8(14.5)$ \\
\hline Sensory deficit & $1(1.8)$ \\
\hline \multicolumn{2}{|l|}{ Persistent neurological deficits } \\
\hline Radicular pain & $3(5.5)$ \\
\hline Motor deficit & $1(1.8)$ \\
\hline Sensory deficit & $0(0.0)$ \\
\hline Surgical PJK & $8(14.5)$ \\
\hline \multicolumn{2}{|l|}{ Intraop complication } \\
\hline Durotomy & $20(36.4)$ \\
\hline Acute hemolytic transfusion reaction & $1(1.8)$ \\
\hline Myocardial ischemia & $1(1.8)$ \\
\hline \multicolumn{2}{|l|}{ Early postop complication (<6 wks) } \\
\hline Delirium & $7(12.7)$ \\
\hline Hyponatremia & $4(7.3)$ \\
\hline Respiratory distress & $7(12.7)$ \\
\hline Pulmonary embolism & $2(3.6)$ \\
\hline Deep vein thrombosis & $2(3.6)$ \\
\hline Pneumonia & $1(1.8)$ \\
\hline Arrhythmia & $2(3.6)$ \\
\hline Myocardial infarction & $1(1.8)$ \\
\hline Urinary tract infection & $4(7.3)$ \\
\hline \multicolumn{2}{|l|}{ Wound complication } \\
\hline Deep wound infection & $1(1.8)$ \\
\hline Superficial/suprafascial wound infection & $2(3.6)$ \\
\hline Wound dehiscence or seroma (no infection) & $3(5.5)$ \\
\hline
\end{tabular}

PJK = proximal junctional kyphosis.

* Sixteen RFs in 15 patients since one patient had both L4-5 and L5-S1 RFs.

osteotomy closure in one patient. In this case, the operative area was inspected and there was no evidence of excessive neural compression. The case proceeded without loss of correction, and the patient had no postoperative motor or sensory deficits.

Durotomy, acute hemolytic transfusion reaction, and myocardial ischemia were documented in $36.4 \%$ (20/55), $1.8 \%(1 / 55)$, and $1.8 \%(1 / 55)$ of patients during surgery, respectively. Early postoperative complications were as fol- lows: delirium (12.7\% [7/55]), hyponatremia (7.3\% [4/55]), respiratory distress $(12.7 \%$ [7/55]), pulmonary embolism (3.6\% [2/55]), deep vein thrombosis $(3.6 \%$ [2/55]), pneumonia $(1.8 \%$ [1/55]), cardiac arrhythmia (3.6\% [2/55]), myocardial infarction $(1.8 \%$ [1/55]), and urinary tract infection $(7.3 \%$ [4/55]). Wound complications included deep wound infection $(1.8 \%$ [1/55]), superficial or suprafascial wound infection $(3.6 \%[2 / 55])$, and wound dehiscence or seroma without infection $(5.5 \%$ [3/55]).

Revision surgery for proximal junctional kyphosis (PJK) occurred in $14.5 \%(8 / 55)$ of patients. Overall reoperation rate was $40 \%$ (22/55). Table 3 summarizes the complications associated with this study.

\section{Predictors of RF or PA}

Predictors of RF or PA are presented in Table 4. On univariate analysis, only accessory supplemental rods (3or 4-rod constructs spanning the ePSO site) were significantly associated with cases of intact rods without PA $(\mathrm{p}=$ $0.004)$. Other variables tested in Table 4 were not significantly different between patients with RF or PA and those without. Variables associated with $p<0.15$ on univariate analysis were included in the multivariable binary logistic regression model. Only the use of accessory supplemental rods (connected to the primary rods) spanning the ePSO site remained a significant predictor for avoiding postoperative RF or PA at the level of the ePSO (OR $0.062,95 \%$ CI $0.007-0.553, \mathrm{p}=0.013$ ).

The protective effect of accessory supplemental rods to avoid RF or PA approached statistical significance on Kaplan-Meier analysis $(\mathrm{p}=0.053, \log$-rank test). Figure 3 shows the probability distribution functions for all patients dichotomized based on the use of accessory supplemental rods.

\section{Interbody Cage Placement at the Osteotomy Increases Segmental Lordosis}

Interbody cage placement at the ePSO site resulted in greater ePSO segmental lordosis correction $\left(45^{\circ}\right.$ vs $35^{\circ}, \mathrm{p}$ $=0.007)$ without a significant difference in RF or PA (p $=0.304)$. Patients with cage placement lost slightly more segmental lordosis than those without cage placement at the last follow-up $\left(1.5^{\circ}\right.$ vs $\left.0.8^{\circ}, \mathrm{p}=0.025\right)$. Table 5 summarizes these results.

\section{Discussion}

Three-column spinal osteotomies, such as the conventional or traditional PSO (Schwab grade 3 osteotomy), ${ }^{35}$ are technically challenging operations for correcting severe rigid spinal deformities. Traditional PSO in the lumbar spine was first described by Thomasen in 1985 for the management of 11 patients with severe disabling ankylosing spondylitis. ${ }^{46}$ Since then, the traditional PSO technique has been used for surgical correction of rigid spinal deformities of various etiologies. ${ }^{1,6,48}$ In 2001, Berven and colleagues performed traditional lumbar PSO in 13 consecutive patients with rigid spinal deformities secondary to iatrogenic flat back syndrome, adult or idiopathic scoliosis, postinfectious kyphosis, and ankylosing spondylitis (just three patients); the authors reported a mean improvement 


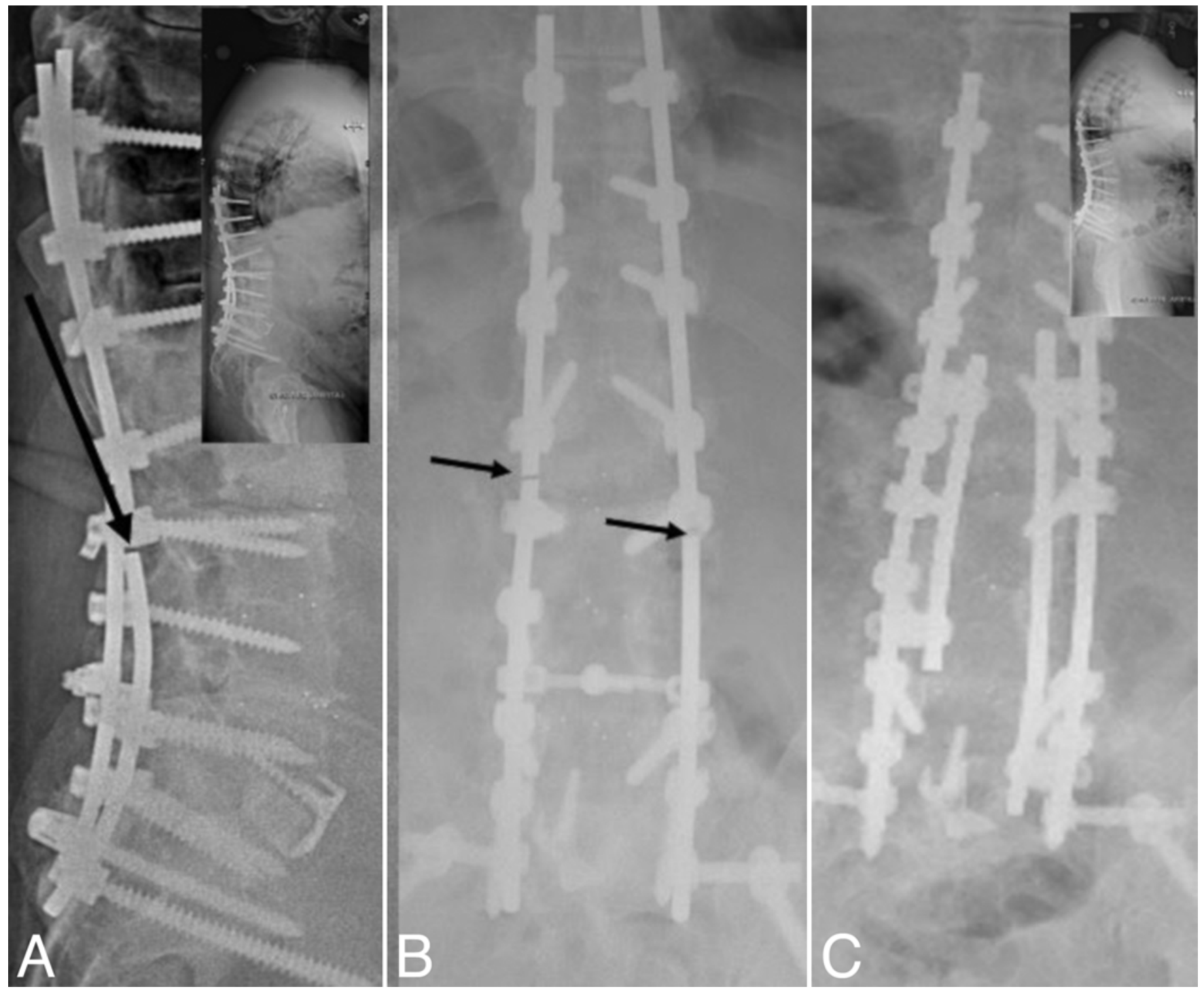

FIG. 2. This case demonstrates postoperative bilateral RFs at L2-3 after T10-iliac posterior instrumentation and fusion with $L 2$ ePSO for adult idiopathic scoliosis. Approximately 3 years after the index operation, the patient presented with increasing low-back pain and muscle spasms. Note the bilateral RFs (arrows) at L2-3 adjacent to the ePSO (A and B). The patient underwent revision surgery with replacement of both primary rods and placement of two accessory supplemental rods across the original osteotomy level (C). During surgery, PA was noted at the L2-3 osteotomy level. The patient recovered from the revision operation without complication, and symptoms resolved.

of approximately $30^{\circ}$ in overall LL at the 2-year followup. ${ }^{1}$ Further studies have demonstrated that the traditional PSO at a single lumbar vertebra can achieve approximately $25^{\circ}-35^{\circ}$ of segmental correction across the osteotomy site, ${ }^{5,6,15-17,20,25,28,30,33,34,48}$ which can improve overall LL by up to $40^{\circ}, 5,16,25,30,47,48$ and can restore harmonious global sagittal alignment with up to $15 \mathrm{~cm}$ of SVA (C7 plumbline) improvement. $.15,16,20,25,28,30,33,34,47$

To the best of our knowledge, the present study is the first focused investigation of the ePSO technique for a substantial number of ASD patients with FSM. Our results suggest that by modifying traditional PSO techniques and extending the posterior wedge resection osteotomy to include the adjacent superior disc, even greater segmental correction $\left(>40^{\circ}\right)$ may be achieved across the osteotomy (Table 2). Extended PSO also takes out an open disc space, which may reduce the risk of PA. Furthermore, placement of a cage or interbody spacer at the osteotomy site may produce even greater segmental correction; we demonstrated that this difference in segmental correction is approximately $10^{\circ}$ when compared to ePSO without cage placement (Table 5). We hypothesize that proper placement of an interbody cage spacer produces a fulcrum or robust pivot point at the anterior spinal column at the ePSO-by which cantilever and compressive forces can then produce substantial lordotic correction. As in previous reports on traditional PSO, the most common level of ePSO in the present study was L3. ${ }^{16,19,25,30}$ 


\begin{tabular}{|c|c|c|c|c|c|c|}
\hline \multirow[b]{2}{*}{ Variable } & \multicolumn{3}{|c|}{ Univariate Analysis } & \multicolumn{3}{|c|}{ Binary Logistic Regression } \\
\hline & $\begin{array}{l}\text { Intact rods w/o PA at } \\
\text { ePSO site }(n=45)\end{array}$ & $\begin{array}{l}\text { RF or PA at ePSO } \\
\text { site }(n=10)\end{array}$ & $\begin{array}{c}\mathrm{p} \\
\text { Value }^{*}\end{array}$ & OR & $95 \% \mathrm{Cl}$ & $\begin{array}{c}p \\
\text { Value }\end{array}$ \\
\hline Age at op in yrs & $63.7 \pm 11.6$ & $65.5 \pm 7.4$ & 0.636 & - & - & - \\
\hline Body mass index in $\mathrm{kg} / \mathrm{m}^{2}$ & $30.3 \pm 6.9$ & $29.8 \pm 10.8$ & 0.900 & - & - & - \\
\hline No. of instrumented vertebrae & $12.0 \pm 3.2$ & $11.2 \pm 2.9$ & 0.468 & - & - & - \\
\hline Postop SVA in ${ }^{\circ}$ & $4.2 \pm 3.5$ & $5.2 \pm 3.0$ & 0.397 & - & - & - \\
\hline Postop PI-LL mismatch in ${ }^{\circ}$ & $10.9 \pm 9.5$ & $16.3 \pm 12.4$ & 0.134 & 1.059 & $0.982-1.143$ & 0.137 \\
\hline Postop LL in ${ }^{\circ}$ & $47.8 \pm 9.9$ & $45.3 \pm 9.9$ & 0.474 & - & - & - \\
\hline Postop ePSO segmental lordosis in ${ }^{\circ}$ & $34.0 \pm 8.8$ & $31.4 \pm 7.6$ & 0.401 & - & - & - \\
\hline $\begin{array}{l}\text { Accessory supplemental rods, 3- or 4-rod } \\
\text { constructs spanning ePSO site }\end{array}$ & $28(62.2)$ & $1(10.0)$ & 0.004 & 0.062 & $0.007-0.553$ & 0.013 \\
\hline Rod diameter in $\mathrm{mm}$ & $5.6 \pm 0.2$ & $5.6 \pm 0.2$ & 0.267 & - & - & - \\
\hline Cobalt chromium rods & $42 \ddagger(97.7)$ & $10(100.0)$ & 1.000 & - & - & - \\
\hline
\end{tabular}

Values expressed as the mean \pm standard deviation or number (percent) for continuous and categorical variables, respectively. Boldface type indicates statistical significance.

* Comparison of cohorts with independent samples t-test or Fisher exact test.

$\dagger$ Multivariable analysis using variables with $p<0.15$ on univariate comparisons ( $p=0.887$, Hosmer-Lemeshow goodness-of-fit test).

$\ddagger$ Rod material not recorded for two patients.

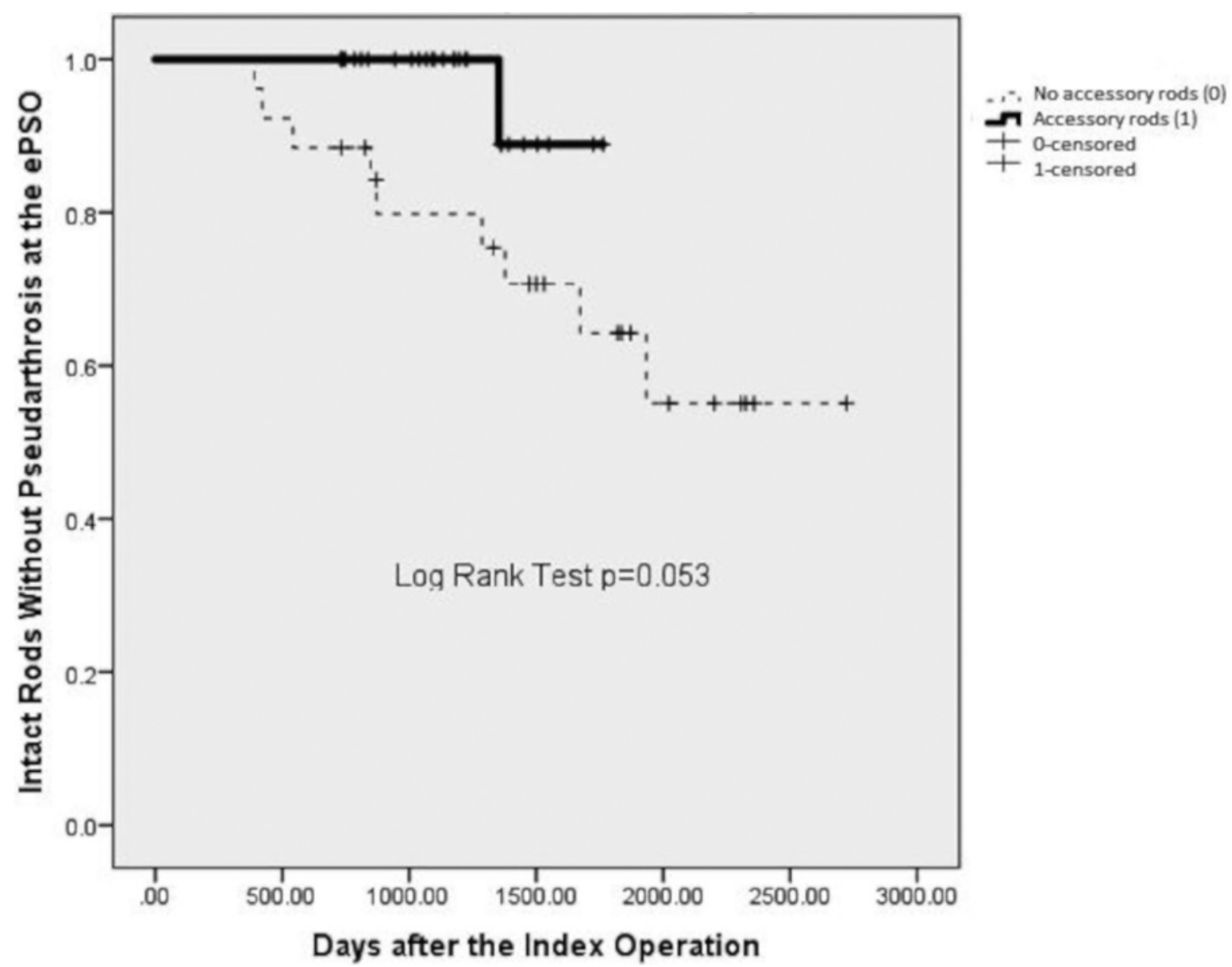

FIG. 3. The protective effect of accessory supplemental rods to avoid RF or PA approached statistical significance on KaplanMeier analysis ( $p=0.053$, log-rank test). The figure demonstrates Kaplan-Meier curves or probability distribution functions for all patients dichotomized based on the use of accessory supplemental rods. 
TABLE 5. Univariate analysis with patients dichotomized based on interbody cage placement at the ePSO site

\begin{tabular}{lccc}
\hline \multicolumn{1}{c}{ Parameter } & $\begin{array}{c}\text { Interbody } \\
\text { Cage }(\mathrm{n}=31)\end{array}$ & $\begin{array}{c}\text { No Interbody } \\
\text { Cage }(\mathrm{n}=24)\end{array}$ & $\begin{array}{c}\mathrm{p} \\
\text { Value* }\end{array}$ \\
\hline $\begin{array}{l}\text { Initial postop change in } \\
\text { ePSO segmental lordosis } \\
\text { compared to preop }\left(^{\circ}\right)\end{array}$ & $-44.8 \pm 13.4$ & $-35.0 \pm 12.3$ & 0.007 \\
\hline $\begin{array}{l}\text { ePSO segmental lordosis at } \\
\text { last FU compared to early } \\
\text { postop }\left(^{\circ}\right)\end{array}$ & $1.5 \pm 2.9$ & $-0.8 \pm 4.1$ & 0.025 \\
\hline RF or PA at ePSO site & $4(12.9)$ & $6(25)$ & 0.304 \\
\hline $\begin{array}{l}\text { Values expressed as the mean } \pm \text { standard deviation or number (\%) for continu- } \\
\text { ous variables and categorical variables, respectively. Boldface type indicates } \\
\text { statistical significance. }\end{array}$ & & \\
* Comparison of cohorts with independent samples t-test or Fisher exact test.
\end{tabular}

Although the PSO technique can provide powerful alignment correction in ASD, procedures involving the technique are associated with high complication rates despite continued improvements in surgical technique, instrumentation, and perioperative management. . $^{8,10,11,14,39,42,43}$ In a prospective multicenter series of consecutive ASD patients, Smith and colleagues reported RF rates ranging from $10.0 \%$ to $31.6 \%$ across centers ${ }^{43}$ Other retrospective studies have reported RF rates of $22 \%-32 \%$ and that RF most commonly occurs adjacent to the PSO..$^{26,38,42}$ Since our ePSO technique may obtain greater focal angulation than that reported for traditional PSO, we hypothesize that a higher theoretical risk of RF or PA is associated with ePSO secondary to increased rod contouring. In support of this hypothesis, Tang and colleagues reported that the fatigue life of posterior spinal fixation rods depends largely on the severity of rod angulation used to maintain the vertebral angle created by the PSO and is significantly lowered by rod contouring. ${ }^{45}$ Despite the possible heightened theoretical risks, however, we report an RF rate after ePSO (18.2\% adjacent to ePSO; $27.3 \%$ overall) that appears comparable to that of traditional PSO (Table 3). ${ }^{26,42,43}$ Moreover, our PA rate for ePSO (14.5\% adjacent to ePSO; $21.8 \%$ overall) appears comparable to that for traditional PSOwhich ranges from $5 \%$ to $27 \%$, $5,15,19,20,26,27,42$ and may occur most commonly adjacent to the osteotomy followed by the lumbosacral junction. ${ }^{19,43}$ Dickson and colleagues suggested that most PA after lumbar PSO occurs within the first 2 years: ${ }^{19}$ however, in the present study, we reported a relatively longer time to PA detection: $3.2 \pm 1.6$ years (range 1.1-6.5 years).

Multiple rod constructs spanning the PSO site may reduce the occurrence of RF or PA. ${ }^{26,27}$ In our cohort, $53 \%$ (29/55) had accessory supplemental rods across the ePSO site (Table 4). We demonstrated that this technique significantly reduced the occurrence of RF or PA on univariate $(\mathrm{p}=0.004)$ and multivariable analyses (OR $0.062,95 \%$ CI $0.007-0.553, p=0.013)$; this effect approached statistical significance on Kaplan-Meier analysis ( $\mathrm{p}=0.053$, log-rank test; Fig. 3).

Other commonly reported complications after traditional PSO include revision surgery for PJK and transient versus persistent neurological deficits. For traditional PSO, rates of transient neurological deficits range from $8 \%$ to $24 \% 17,20,28,33,42,50$ and delayed or persistent neurological deficits range from $2 \%$ to $11 \% .{ }^{20,39,42}$ These rates appear comparable to those in the present study; we reported that transient and persistent motor deficits occurred in $14.5 \%$ $(8 / 55)$ and $1.8 \%(1 / 55)$ of patients, respectively (Table 3$)$. Our surgical PJK rate was $14.5 \%(8 / 55)$, which again is comparable to the rates in traditional PSO studies (range $2.3 \%-14 \%){ }^{20,25,28,42}$ There is increasing evidence that greater alignment correction in the lumbar spine, especially with PSO, predisposes to a higher risk of PJK. ${ }^{32} \mathrm{We}$ recommend that patients have routine interval follow-up with long-cassette standing scoliosis radiographs to monitor for this possible postoperative complication.

We interpreted results of the present study to suggest that lumbar ePSO in appropriately selected ASD patients with FSM may produce greater segmental correction than that in traditional PSO but with comparable complication rates. We suggest that the ideal candidates for ePSO are patients with rigid spinal deformities requiring a large magnitude of correction of more than $35^{\circ}$ after single-level osteotomy. We have provided evidence to suggest that interbody cage placement at the ePSO allows additional lordotic correction approaching $50^{\circ}$ across the single osteotomy site and that accessory supplemental rods reduce the incidence of RF or PA.

Although still classified as Schwab grade 3 osteotomy, closing-opening wedge osteotomies or "fish-mouth" PSO, which Park and colleagues performed in 15 FSM patients, can achieve mean PSO segmental correction of $42.9^{\circ} \pm$ $13.7^{\circ} .{ }^{33}$ In that study, only $43 \%$ of the patients had prior spine surgery (compared to $96 \%$ in our present study), a higher percentage of fish-mouth PSOs were thoracic compared to traditional PSOs (27\% vs $8 \%$ ), the minimum 6-month follow-up was short, and the duration of the study follow-up was not specified; ${ }^{33}$ therefore, these factors may limit meaningful comparison of RF or PA rates for fishmouth PSO with the rates for other PSO techniques. Also, we hypothesize that leaving a fish-mouth bony defect at the index vertebra may predispose to higher RF or PA rates. Park et al. proposed increased theoretical risks of vascular complication associated with the anterior opening to create the fish-mouth defect. ${ }^{33}$ Fish-mouth PSO uses the middle spinal column as the pivot point for lordotic correction. In comparison, our ePSO+cage technique relies on the anterior column as the fulcrum and potentially circumvents the increased risks of RF or PA and the vascular complication associated with fish-mouth PSO. However, a prospective trial with a direct comparison is necessary before reaching definitive conclusions on the appropriate indications for both of these modified PSO techniques.

The present study is limited by the patient selection, treatment, and referral biases that are inherent to a singlecenter, retrospective cohort study. Also, as with many studies based on radiographic outcomes, our study is limited by imaging technique and quality; however, we excluded poor-quality radiographs and utilized standard technique for obtaining long-cassette scoliosis radiographs. Although we provide evidence to suggest improved segmental lordotic correction with comparable complication rates, a prospective trial with direct comparison is necessary before 
reaching definitive conclusions on the appropriate indications for traditional versus extended PSO. Also, future research with patient-reported clinical outcome measures are necessary to further validate the ePSO technique. Finally, recording blood loss and exact operative duration of the ePSO technique (rather than only for the entire operation) may also allow improved comparison to traditional PSO.

\section{Conclusions}

Extended PSO is an effective technique to correct FSM for ASD. In comparison to traditional PSO techniques, ePSO may allow greater focal correction (our results demonstrate mean segmental angular correction greater than $40^{\circ}$ at the ePSO level) with comparable complication rates, especially with interbody cage placement at the ePSO site and the use of accessory supplemental rods.

\section{References}

1. Berven SH, Deviren V, Smith JA, Emami A, Hu SS, Bradford DS: Management of fixed sagittal plane deformity: results of the transpedicular wedge resection osteotomy. Spine (Phila Pa 1976) 26:2036-2043, 2001

2. Boachie-Adjei O: Role and technique of eggshell osteotomies and vertebral column resections in the treatment of fixed sagittal imbalance. Instr Course Lect 55:583-589, 2006

3. Booth KC, Bridwell KH, Lenke LG, Baldus CR, Blanke KM: Complications and predictive factors for the successful treatment of flatback deformity (fixed sagittal imbalance). Spine (Phila Pa 1976) 24:1712-1720, 1999

4. Bradford DS, Tribus CB: Current concepts and management of patients with fixed decompensated spinal deformity. Clin Orthop Relat Res (306):64-72, 1994

5. Bridwell KH, Lewis SJ, Edwards C, Lenke LG, Iffrig TM, Berra A, et al: Complications and outcomes of pedicle subtraction osteotomies for fixed sagittal imbalance. Spine (Phila Pa 1976) 28:2093-2101, 2003

6. Bridwell KH, Lewis SJ, Lenke LG, Baldus C, Blanke K: Pedicle subtraction osteotomy for the treatment of fixed sagittal imbalance. J Bone Joint Surg Am 85-A:454-463, 2003

7. Bridwell KH, Lewis SJ, Rinella A, Lenke LG, Baldus C, Blanke K: Pedicle subtraction osteotomy for the treatment of fixed sagittal imbalance. Surgical technique. J Bone Joint Surg Am 86-A (Suppl 1):44-50, 2004

8. Buell TJ, Buchholz AL, Quinn JC, Bess S, Line BG, Ames $\mathrm{CP}$, et al: A pilot study on posterior polyethylene tethers to prevent proximal junctional kyphosis after multilevel spinal instrumentation for adult spinal deformity. Oper Neurosurg (Hagerstown) [epub ahead of print], 2018

9. Buell TJ, Buchholz AL, Quinn JC, Mullin JP, Garces J, Mazur MD, et al: Extended asymmetrical pedicle subtraction osteotomy for adult spinal deformity: 2-dimensional operative video. Oper Neurosurg (Hagerstown) [epub ahead of print], 2018

10. Buell TJ, Chen CJ, Quinn JC, Buchholz AL, Mazur MD, Mullin JP, et al: Alignment risk factors for proximal junctional kyphosis and the effect of lower thoracic junctional tethers for adult spinal deformity. World Neurosurg [epub ahead of print], 2018

11. Buell TJ, Mullin JP, Nguyen JH, Taylor DG, Garces J, Mazur MD, et al: A novel junctional tether weave technique for adult spinal deformity: 2-dimensional operative video. Oper Neurosurg (Hagerstown) [epub ahead of print], 2018

12. Burton DC: Smith-Petersen osteotomy of the spine. Instr Course Lect 55:577-582, 2006

13. Casey MP, Asher MA, Jacobs RR, Orrick JM: The effect of
Harrington rod contouring on lumbar lordosis. Spine (Phila Pa 1976) 12:750-753, 1987

14. Charosky S, Guigui P, Blamoutier A, Roussouly P, Chopin D: Complications and risk factors of primary adult scoliosis surgery: a multicenter study of 306 patients. Spine (Phila Pa 1976) 37:693-700, 2012

15. Cho KJ, Bridwell KH, Lenke LG, Berra A, Baldus C: Comparison of Smith-Petersen versus pedicle subtraction osteotomy for the correction of fixed sagittal imbalance. Spine (Phila Pa 1976) 30:2030-2038, 2005

16. Cho KJ, Kim KT, Kim WJ, Lee SH, Jung JH, Kim YT, et al: Pedicle subtraction osteotomy in elderly patients with degenerative sagittal imbalance. Spine (Phila Pa 1976) 38:E1561E1566, 2013

17. Choi HY, Hyun SJ, Kim KJ, Jahng TA, Kim HJ: Surgical and radiographic outcomes after pedicle subtraction osteotomy according to surgeon's experience. Spine (Phila Pa 1976) 42:E795-E801, 2017

18. Cummine JL, Lonstein JE, Moe JH, Winter RB, Bradford DS: Reconstructive surgery in the adult for failed scoliosis fusion. J Bone Joint Surg Am 61:1151-1161, 1979

19. Dickson DD, Lenke LG, Bridwell KH, Koester LA: Risk factors for and assessment of symptomatic pseudarthrosis after lumbar pedicle subtraction osteotomy in adult spinal deformity. Spine (Phila Pa 1976) 39:1190-1195, 2014

20. Eskilsson K, Sharma D, Johansson C, Hedlund R: Pedicle subtraction osteotomy: a comprehensive analysis in 104 patients. Does the cause of deformity influence the outcome? J Neurosurg Spine 27:56-62, 2017

21. Farcy JP, Schwab FJ: Management of flatback and related kyphotic decompensation syndromes. Spine (Phila Pa 1976) 22:2452-2457, 1997

22. Gill JB, Levin A, Burd T, Longley M: Corrective osteotomies in spine surgery. J Bone Joint Surg Am 90:2509-2520, 2008

23. Glassman SD, Berven S, Bridwell K, Horton W, Dimar JR: Correlation of radiographic parameters and clinical symptoms in adult scoliosis. Spine (Phila Pa 1976) 30:682-688, 2005

24. Glassman SD, Bridwell K, Dimar JR, Horton W, Berven S, Schwab F: The impact of positive sagittal balance in adult spinal deformity. Spine (Phila Pa 1976) 30:2024-2029, 2005

25. Gupta MC, Ferrero E, Mundis G, Smith JS, Shaffrey CI, Schwab F, et al: Pedicle subtraction osteotomy in the revision versus primary adult spinal deformity patient: is there a difference in correction and complications? Spine (Phila Pa 1976) 40:E1169-E1175, 2015

26. Gupta S, Eksi MS, Ames CP, Deviren V, Durbin-Johnson B, Smith JS, et al: A novel 4-rod technique offers potential to reduce rod breakage and pseudarthrosis in pedicle subtraction osteotomies for adult spinal deformity correction. Oper Neurosurg (Hagerstown) 14:449-456, 2018

27. Hyun SJ, Lenke LG, Kim YC, Koester LA, Blanke KM: Comparison of standard 2-rod constructs to multiple-rod constructs for fixation across 3-column spinal osteotomies. Spine (Phila Pa 1976) 39:1899-1904, 2014

28. Kim YC, Lenke LG, Hyun SJ, Lee JH, Koester LA, Blanke KM: Results of revision surgery after pedicle subtraction osteotomy for fixed sagittal imbalance with pseudarthrosis at the prior osteotomy site or elsewhere: minimum 5 years postrevision. Spine (Phila Pa 1976) 39:1817-1828, 2014

29. Kim YJ, Bridwell KH, Lenke LG, Cheh G, Baldus C: Results of lumbar pedicle subtraction osteotomies for fixed sagittal imbalance: a minimum 5-year follow-up study. Spine (Phila Pa 1976) 32:2189-2197, 2007

30. Lafage V, Schwab F, Vira S, Hart R, Burton D, Smith JS, et al: Does vertebral level of pedicle subtraction osteotomy correlate with degree of spinopelvic parameter correction? J Neurosurg Spine 14:184-191, 2011 
31. Lagrone MO, Bradford DS, Moe JH, Lonstein JE, Winter RB, Ogilvie JW: Treatment of symptomatic flatback after spinal fusion. J Bone Joint Surg Am 70:569-580, 1988

32. Nguyen NL, Kong CY, Hart RA: Proximal junctional kyphosis and failure-diagnosis, prevention, and treatment. Curr Rev Musculoskelet Med 9:299-308, 2016

33. Park JH, Hyun SJ, Kim KJ, Jahng TA: Comparative study between pedicle subtraction osteotomy (PSO) and closingopening wedge osteotomy (fish-mouth PSO) for sagittal plane deformity correction. Spine (Phila Pa 1976) 42:E899-E905, 2017

34. Popa I, Oprea M, Andrei D, Mercedesz P, Mardare M, Poenaru DV: Utility of the pedicle subtraction osteotomy for the correction of sagittal spine imbalance. Int Orthop 40:12191225,2016

35. Schwab F, Blondel B, Chay E, Demakakos J, Lenke L, Tropiano P, et al: The comprehensive anatomical spinal osteotomy classification. Neurosurgery 74:112-120, 2014

36. Schwab F, Patel A, Ungar B, Farcy JP, Lafage V: Adult spinal deformity-postoperative standing imbalance: how much can you tolerate? An overview of key parameters in assessing alignment and planning corrective surgery. Spine (Phila Pa 1976) 35:2224-2231, 2010

37. Schwab FJ, Smith VA, Biserni M, Gamez L, Farcy JP, Pagala M: Adult scoliosis: a quantitative radiographic and clinical analysis. Spine (Phila Pa 1976) 27:387-392, 2002

38. Smith JS, Klineberg E, Lafage V, Shaffrey CI, Schwab F, Lafage R, et al: Prospective multicenter assessment of perioperative and minimum 2-year postoperative complication rates associated with adult spinal deformity surgery. J Neurosurg Spine 25:1-14, 2016

39. Smith JS, Sansur CA, Donaldson WF III, Perra JH, Mudiyam R, Choma TJ, et al: Short-term morbidity and mortality associated with correction of thoracolumbar fixed sagittal plane deformity: a report from the Scoliosis Research Society Morbidity and Mortality Committee. Spine (Phila Pa 1976) 36:958-964, 2011

40. Smith JS, Shaffrey CI, Berven S, Glassman S, Hamill C, Horton W, et al: Improvement of back pain with operative and nonoperative treatment in adults with scoliosis. Neurosurgery 65:86-94, 2009

41. Smith JS, Shaffrey CI, Berven S, Glassman S, Hamill C, Horton W, et al: Operative versus nonoperative treatment of leg pain in adults with scoliosis: a retrospective review of a prospective multicenter database with two-year follow-up. Spine (Phila Pa 1976) 34:1693-1698, 2009

42. Smith JS, Shaffrey CI, Klineberg E, Lafage V, Schwab F, Lafage R, et al: Complication rates associated with 3-column osteotomy in 82 adult spinal deformity patients: retrospective review of a prospectively collected multicenter consecutive series with 2-year follow-up. J Neurosurg Spine 27:444457, 2017

43. Smith JS, Shaffrey E, Klineberg E, Shaffrey CI, Lafage V, Schwab FJ, et al: Prospective multicenter assessment of risk factors for rod fracture following surgery for adult spinal deformity. J Neurosurg Spine 21:994-1003, 2014

44. Steyerberg EW, Vickers AJ, Cook NR, Gerds T, Gonen M, Obuchowski N, et al: Assessing the performance of prediction models: a framework for traditional and novel measures. Epidemiology 21:128-138, 2010
45. Tang JA, Leasure JM, Smith JS, Buckley JM, Kondrashov D, Ames CP: Effect of severity of rod contour on posterior rod failure in the setting of lumbar pedicle subtraction osteotomy (PSO): a biomechanical study. Neurosurgery 72:276-283, 2013

46. Thomasen E: Vertebral osteotomy for correction of kyphosis in ankylosing spondylitis. Clin Orthop Relat Res (194):142152,1985

47. Toyone T, Shiboi R, Ozawa T, Inada K, Shirahata T, Kamikawa K, et al: Asymmetrical pedicle subtraction osteotomy for rigid degenerative lumbar kyphoscoliosis. Spine (Phila Pa 1976) 37:1847-1852, 2012

48. Wang MY, Berven SH: Lumbar pedicle subtraction osteotomy. Neurosurgery 60 (2 Suppl 1):ONS140-ONS146, 2007

49. Yagi M, King AB, Cunningham ME, Boachie-Adjei O: Long-term clinical and radiographic outcomes of pedicle subtraction osteotomy for fixed sagittal imbalance: does level of proximal fusion affect the outcome? Minimum 5-year follow-up. Spine Deform 1:123-131, 2013

50. Zhang Z, Wang H, Zheng W: Postoperative dysesthesia in lumbar three-column resection osteotomies. Eur Spine J 25:2622-2628, 2016

\section{Disclosures}

Dr. C. I. Shaffrey has been a consultant for Medtronic, Nuvasive, Zimmer Biomet, and $\mathrm{K} 2 \mathrm{M}$; has received royalties from Medtronic, Nuvasive, and Zimmer Biomet; is a stock holder in Nuvasive; and has received grants from the NIH, Department of Defense, and the North American Clinical Trials Network for non-studyrelated effort. Dr. Smith has received royalties from Zimmer Biomet; has been a consultant for Zimmer Biomet, Cerapedics, Nuvasive, K2M, and AlloSource; has received honoraria from Zimmer Biomet, Nuvasive, and K2M; has received support from DePuy Synthes for the study described; has received support from DePuy Synthes and ISSGF for non-study-related effort; and has received fellowship support from the NREF and AOSpine.

\section{Author Contributions}

Conception and design: Buell, CI Shaffrey, Smith. Acquisition of data: Buell, Nguyen, Mazur, Mullin, Garces, Taylor. Analysis and interpretation of data: Buell, Nguyen, Mazur, Mullin, Garces, Taylor, CI Shaffrey, Smith. Drafting the article: Buell. Critically revising the article: all authors. Reviewed submitted version of manuscript: all authors. Approved the final version of the manuscript on behalf of all authors: Buell. Statistical analysis: Buell.

\section{Correspondence}

Thomas J. Buell: University of Virginia Health System, Charlottesville, VA.tjb4p@hscmail.mcc.virginia.edu. 